\title{
EXTENDED DRUG RESISTANCE IN CHILDREN WITH TYPHOID FEVER.
}

1. MBBS, FCPS

Assistant Professor

Ziauddin University Hospital (ZUH)

2. MBBS, FCPS

Assistant Professor

Ziauddin University Hospital (ZUH)

3. MBBS, FCPS (Patho)

Ziauddin University Hospital (ZUH)

4. MBBS

Final Year Student

Ziauddin University Hospital (ZUH).

5. MBBS, DCH

Registrar

Ziauddin University Hospital (ZUH)

6. MBBS

Final Year Student

Ziauddin University Hospital (ZUH)

7. MBBS, FCPS (Peads)

Ziauddin University Hospital (ZUH).

Correspondence Address:

Dr. Tayyab Anwar

Ziauddin University Hospital (ZUH)

tayyaba679@gmail.com

Article received on:

10/05/2019

Accepted for publication:

03/12/2019

\begin{abstract}
Tayyaba Anwar ${ }^{1}$, Heena Rais ${ }^{2}$, Madiha Fatima Jamil ${ }^{3}$, Saba Safdar ${ }^{4}$, Muhammad Rafay Amir ${ }^{5}$,
\end{abstract} Ahmed Altaf ${ }^{6}$, Hira Khan ${ }^{7}$

ABSTRACT... In developing countries, typhoid fever is mostly seen due to poor public health and low socioeconomic indices. Currently Pakistan is going through the largest outbreak of XDR typhoid fever which has resulted in increased morbidity and mortality especially in pediatric population. Objectives: To see the pattern of extended drug resistant typhoid fever in different areas of Karachi. Study Design: Cross sectional study. Setting: Department of pediatrics, Ziauddin Hospital (KDLB, NORTH, CLIFTON campus). Period: 6 months from October 2018 till March 2019. Material \& Methods: All patients who presented with history of fever for 3 or more days with signs and symptoms of typhoid fever were recruited. For data collection a self-structured questionnaire was used. Age, gender, socioeconomic status, personal hygiene, water supply and sanitation were taken into account. Blood samples were sent for cultures. Salmonella isolates were tested for antibiotic susceptibility. Tested antimicrobials were ampicillin, TMP/SMX, cefixime, ceftriaxone, aztreonam, ciprofloxacin, azithromycin, meropenem. For data analysis SPSS version 22 was used. Results: Out of 415 patients, 235 had culture proven typhoid fever. Salmonella typhi was isolated in $94.4 \%$ of the patients and salmonella paratyphi was isolated in $5.57 \%$. Of the 235 , Males were $62 \%$ and females were $42.4 \%$. Major determinants associated with acquiring salmonella infection were young age (74\%), male sex (62\%), middle and low socioeconomic status (83.8\%), living in west district of Karachi $(54.9 \%)$ and drinking line water (79.2\%). Extended drug resistance was encountered in $69.5 \%$. Most of the isolates were sensitive to meropenem and azithromycin ( $96.7 \%$, and $95.5 \%$ respectively). Ceftriaxone resistance was prevelant in all three districts of Karachi ( $p$ value $<0.001$ ), in different age groups 1-6yrs (98\%), 7-12 yrs(91\%), 13-18 yrs (100\%) and in males(58\%) predominantly. Conclusion: Karachi is facing an outbreak of XDR typhoid fever. Risk of acquiring extended drug resistant typhoid fever is increased in younger age group 1-6 yrs, males, west district of Karachi and poor socioeconomic status. Drinking unboiled water is identified as one of the major culprits. Actions should be taken at all health care levels to monitor the judicious use of antibiotics, and preventive strategies like safe water supply, improved sanitation along with typhoid vaccination are suggested to overcome this outbreak.

Key words: $\quad$ Azithromycin, Extended-Drug Resistant, Meropenem, Typhoid Fever.

Article Citation: Anwar T, Rais H, Jamil MF, Amir MR, Altaf A, Safdar S, Khan H. Extended drug resistance in children with typhoid fever. Professional Med J 2020; 27(3):581-587. DOI: 10.29309/TPMJ/2020.27.3.3695

\section{INTRODUCTION}

Typhoid fever is major public health problem in developing world. In the year 2000 there were 21.5 million cases worldwide with half of them were from southeast Asia. ${ }^{1}$ It is prevalent in Pakistan, especially in pediatric population of $<10$ years. $^{2}$ In 2014 the annual incidence of Salmonella typhi $A$ and Paratyphoid $A$ was reported to be $451 / 100,000$ and $76 / 100,000$ respectively in children. ${ }^{3}$

With this burden, treating typhoid fever is huge challenge for health care provider in developing countries. Factors like nonspecific signs and symptoms ${ }^{4}$, variable yield of organism on blood culture $^{5}$ and finally drug resistance ${ }^{6}$ are one by one increasing the complexity of managing this disease. Over the past three decades drug susceptibility against Salmonella Typhi and Paratyphi has been changed significantly.

MDR (multi drug resistant) typhoid fever is defined as resistance against three first line drugs including ampicillin, chloramphenicol and TMP- 
SMX. Factually, it was first reported in late 1970 and emerge as huge outbreak in between 1980 and $1990 .{ }^{7}$ In Pakistan it was reported to be $44 \% .{ }^{8}$ After that quinolones overtake as first line therapy for Typhoid fever but In early 2000, emerging resistance against quinolones was increasingly being reported..$^{9-11}$

In these circumstances, third generation cephalosporin both parenteral and oral become drug of choice for treatment of typhoid fever in Pakistan ${ }^{12}$ particularly in pediatric population.

Ceftriaxone resistance was first time reported in South East Asia (Bangladesh) in 11 months old boy in $1999 .{ }^{13}$ From 2009 to 2011 ceftriaxone resistance was found only $0.08 \%$ in two children of Karachi by laboratory surveillance data. ${ }^{8}$

Currently sporadic cases of extended drug resistant typhoid (drug resistance ampicillin, chloramphenicol, cotrimaxole, flouroquinole and ceftriaxone) are frequently being reported from different centers of Sindh especially from Karachi and Hyderabad. We planned to conduct this study to determine the variation of extended drug resistant typhoid fever in all three campuses of Ziauddin Hospital in metropolitan city Karachi so that appropriate actions will be taken to monitor judicious use of antibiotics and to encourage preventive strategies according to management guidelines of typhoid fever.

\section{MATERIAL \& METHODS \\ Setting}

Pediatric unit Ziauddin hospital (KDLB, Clifton and North campus).

\section{Period}

Six months October 2018 till March 2019.

\section{Sample Size}

One seventy two .Sample length was estimated with the use of Open epi sample size calculator as the prevalence of culture proven enteric fever was $13 \%{ }^{14}$ with a confidence interval of $95 \%$.

\section{Inclusion Criteria}

Age one year to 18 year. Both genders Individuals/ caregiver who will give consent for the study. Children who gave the history of fever, lasting for greater than three days without an apparent focus of infection. Clinical suspicion of typhoid fever (high grade fever, malaise, headache, constipation or diarrhea).

\section{Exclusion Criteria}

Children with history of fever lasting three days or more with obvious cognizance of infection like URTI, Otitis Media, and Pneumonia

\section{Study Design}

Cross-sectional study.

\section{Data Collection}

Patients who reported with the history of fever lasting for 3 days or more, without any focus of infection and clinical signs of enteric fever like toxic look headache, anorexia, abdominal discomfort, drowsy, altered consciousness, malaise, constipation, and diarrhea from outpatient department as well as admitted in all three campuses were recruited. A focal person was identified in each campus who entered Information regarding demography, socioeconomic status, signs and symptoms, diagnosis, blood cultures and antibiotic therapy on structured questionnaire. Based on the parents purchasing power parity study population was categorized into 4 socioeconomic classes, Upper, Upper middle, Middle Middle, Lower middle and Lower class. This class stratification was based on criteria provided by Pakistan Institute of development Economics. ${ }^{15}$ An informed written consent was taken from the parents before drawing the blood samples for blood culture.

Three to five $\mathrm{ml}$ of venous blood sample was drawn from the patient for blood culture and will be dispatched to pathology department at the time of admission before starting empirical antibiotic therapy. Later the blood was inoculated into BACTEC bottles. On the basis of visual or BACTEC machine identification, the blood culture samples had been in addition subculture onto MacConkey agar and Blood agar plates. Colonies displaying biochemical reactions indicative of salmonella were proved using 
specific $\mathrm{O}$ and $\mathrm{H}$ antisera. Salmonella isolates have been tested for antibiotic susceptibility using Kirbay-Bauer disc diffusion technique on Mueller Hinton agar with standard antimicrobial discs. Antibiotic susceptibility for ampicillin, TMP/SMX, cefixime, ceftriaxone, aztreonam, ciprofloxacin, azithromycin, meropenem was performed.

\section{Data Analysis}

DatawasanalyzedonSPSSversion22.Quantitative data is reported as mean +/- SD while qualitative data is reported as frequency and percentages. Pattern of drug sensitivity(Extended drug resistance) was compared among different age group, socioeconomic status and geographical location using chi-square test with $p$ value $<0.05$ taken as significant.

\section{RESULTS}

Over the study period from March 2018 to Sep 2018, a total of 415 patients with suspected enteric fever were included for analysis. Out of which 235 came out to be culture proven typhoid fever. Result of 233 culture proven typhoid fever were analyzed as two cases have some missing data in it. Fifty six percent of the patients were culture proven typhoid fever however $43.4 \%$ of the patients had no growth. Of the isolated bacteria 94.4\% (220) were Salmonella typhi and rest 5.57 $\%$ (13) were salmonella Paratyphi A. No Paratyphi $\mathrm{B}$ or $\mathrm{C}$ were isolated .Most of the patients have age group from 1-18 years, while 30 patients were taken in separate age group of more than 18 who were near to complete 19 year. Many bacterial isolates were resistant to ampicillin, cefixime, ciprofloxacin and chloramphenicol (Figure-1).

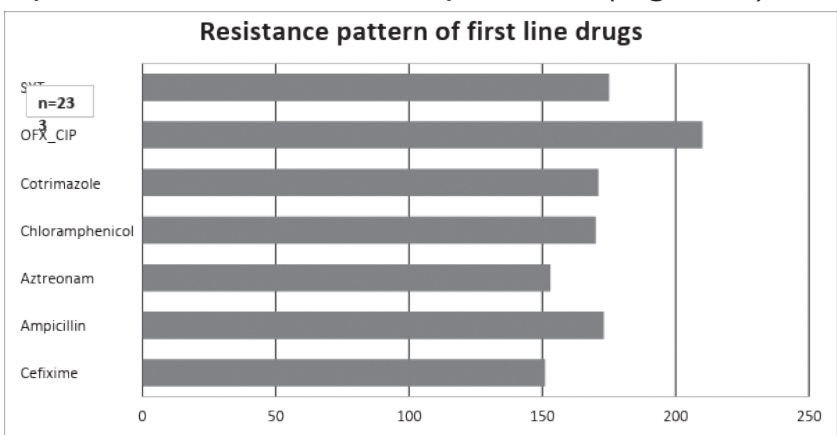

Among culture proven typhoid fever males were $134(62 \%)$ and females were 99 (42.4\%). Majority of the patients $(54.9 \%)$ were from the west $19.6 \%$ from south and $26.1 \%$ from Central district of Karachi.

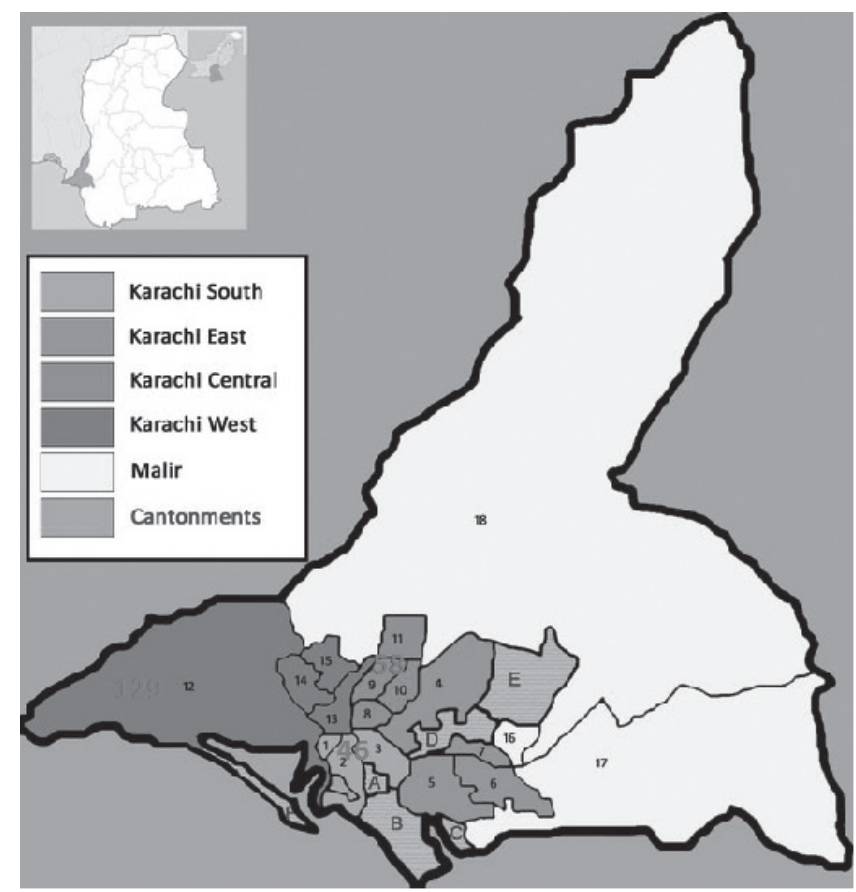

36 patients belonged to upper socioeconomic class whereas 126 and 71 were from the middle and lower socioeconomic class respectively. Fever and coated tongue were the common presentation of typhoid fever in our study population.

\begin{tabular}{|l|c|c|}
\hline \multicolumn{1}{|c|}{ Symptoms } & Frequency & $\%$ \\
\hline Jaundice & 8 & 3.4 \\
\hline Hepatomegaly & 91 & 38.7 \\
\hline Tongue coating & 136 & 57.9 \\
\hline Vomiting & 87 & 37 \\
\hline Constipation & 25 & 10.6 \\
\hline Abdomial pain & 86 & 36.6 \\
\hline Diarrhoea & 50 & 21.3 \\
\hline Fever for three days & 229 & 97.4 \\
\hline \multicolumn{2}{|r|}{ Frequency of Symptoms $\mathbf{( n = 2 3 3 ) .}$} \\
\hline
\end{tabular}

The determinants associated with acquiring salmonella typhi and Paratyphi included young childrenage 1-6 year (74\%) male sex (62\%), middle and low socioeconomic status (83.8\%) and living in west district (54.9\%). There's no significant difference in children acquiring salmonella from line water $(35.6 \%)$ or boiled water $(35.6 \%)$ while remaining were utilizing filter water(28.5\%) but 
XDR typhoid fever cases are more common in consumers of line water $(79.2 \%)$.

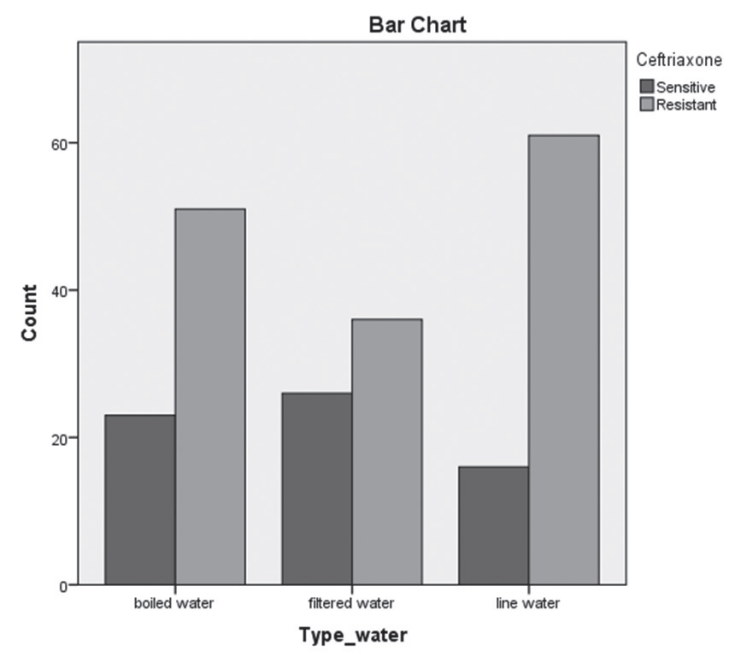

$49(20.6 \%)$ isolated cases had unsatisfactory personal hygiene while $72(30.6 \%)$ had improper disposal of wastage. Family members belong to isolated cases were range from 2-15 with mean of $6.1(+2.48)$.

$69.5 \%$ (148) of isolates showed extended drug resistance. Ceftriaxone resistance was prevalent in west south and central district uniformly ( $p$ value < 0.001). Regarding antibiotic sensitivity, meropenem and azithromycin were sensitive to majority of the isolates i.e. $96.7 \%$, and $95.5 \%$ with no significant difference among three districts of Karachi ( $p$ value 0.589 \&0.516 respectively). Sensitivity to meropenem among different age groups of 1-6 year (98\%), 7-12 year (91\%) and $13-18$ year (100\%). Drug resistance to ceftriaxone is $74 \%, 64.4 \%$ and $73.7 \%$ in all age groups. Males were predominantly sensitive to Meropenum and resistant to Ceftriaxone (58.2\%).

Comparison between Meroneum and Ceftriaxone sensitivity and resistance pattern in different age group

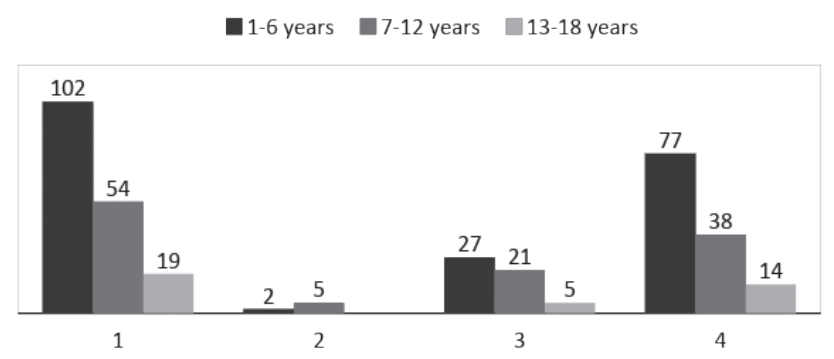

Comparison between Meropeneum and Ceftriaxone sensitivity and resistance pattern

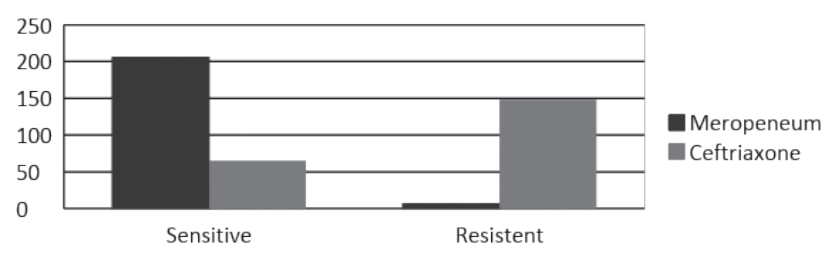

DISCUSSION

Drug resistancetyphoidfever originatesafearsome environment not only in country, but also abroad when cases from UK and USA had reported last year. Historical sensitivity against Salmonella keeps on changing from 1970 when, for the first time, chloramphenicol resistance was reported in Indian subcontinent. ${ }^{16}$ Before 2016, ceftriaxone and cefixime was being recommended as first line antibiotics in complicated and uncomplicated typhoid fever ${ }^{17}$, but sporadic and then cluster of ceftriaxone resistant cases from Sindh province created uncertain situation regarding empirical treatment of Typhoid fever.

Every day, newspapers and social media report about the emergence of superbugs and drug resistant typhoid fever. From different districts of Hyderabad, 92\% confirmed ceftriaxone resistant cases in children (under $15 \mathrm{y} / 0$ ) were reported over a period of one year ${ }^{18}$ as compared to our study in which we have 148 (69.5\%) cases of extended drug resistant typhoid fever over a period of six months. Abbasi Shaheed hospital that represents central district of Karachi also reported 96\% resistance to ceftriaxone in pediatric population. ${ }^{19}$ In children aged 1-6 we had high incidence (74\%) in contrast to $56 \%$ reported from Hyderabad in children (under 5 years), similar to observation from studies from India and Bangladesh. ${ }^{20}$ Children are more prone to acquire resistance because they have less immune responses, receive more empirical treatment and encounter more health care providers. ${ }^{21}$ Similar to studies from other part of subcontinents, India ${ }^{22}$, China ${ }^{23}$, Bangladesh $^{24}$ and parts of Pakistan ${ }^{18}$, male gender has predominance in XDR Typhoid fever. Among risk factors of typhoid fever, drinking unboiled water (either line water directly or after filtration) identified as a leading culprit which is 
similar to previous observations in Karachi ${ }^{25}$ and other parts of the developing world ${ }^{24,26}$, where provision of safe water supply is a huge problem. Our study identified high incidence $(54.6 \%)$ of typhoid fever in children from the west district of Karachi, but to draw global perspective regarding contaminated water supply in any specific area of city, an epidemiologic study on large scale is needed with sampling of water from main reservoir to households.

On the other hand, shift of salmonella sensitivity towards azithromycin and meropenum is evident by our observation and different observations in other parts of province ${ }^{12,19}$ which creates an alarming situation. Considering the current culture sensitivity of Salmonella, it is matter of great concern whether empirical treatment of typhoid fever shift towards azithromycin and meropenum in uncomplicated and complicated cases respectively or if it continues with cefixime and ceftriaxone as first line drugs. In countries like Pakistan where judicial use of antibiotics is not practiced either due to availability of over-counter medicine without any prescription or treating presumed typhoid fever with broad spectrum antibiotics without sending diagnostic test like blood culture, it is very important to design and implement comprehensive treatment guidelines at all health care levels.

The only answer to deal with this outbreak is dissemination and adaptation of preventive strategies through every possible opportunity at individual or mass level. Children under 5 years of age, which are mostly dependent on parents/ caregiver for their necessities, are the most commonly affected age group so it should be the top priority of health care providers to educate parents/caregivers regarding the risk factors of this devastating illness. It is evident that typhoid immunization can reduce disease burdens, especially when given to high-risk age group in identified geographic areas. ${ }^{27}$ Immunization cannot only reduce the number of circulating MDR strains but they can also decrease the incidence of undifferentiated febrile illness, thereby reducing the need for empirical antimicrobial therapy. ${ }^{28}$ Unlike the significant investment required for major infrastructure development, vaccination is relatively more affordable to governments, since it does not require substantial behavioral change and has been shown to be cost-effective. ${ }^{29}$

\section{CONCLUSION}

In conclusion, to overcome this epidemic of XDR typhoid, use of conjugate typhoid vaccines should be integrated with other control strategies: access to safe water supply, sanitation improvements, hygiene education messages, community or national food hygiene measures, and appropriate case and chronic carrier detection and along with proper use of antibiotics to manage these cases and chronic carriers.

\section{Strength of Study}

Diagnosis done by gold standard blood culture. Cases were taken from three different campuses having separate catchment area.

\section{Limitation of Study}

Association of various risk factors can be further strengthened by comparing cases with matched controls.

\section{Copyright@ 03 Dec, 2019.}

\section{REFRENCES}

1. Crump JA, Luby SP, Mintz ED. The global burden of typhoid fever. Bulletin of the World Health Organization. 2004;82:346-53.

2. Cutler D, Miller G. The role of public health improvements in health advances: the twentiethcentury United States. Demography. 2005 Feb 1;42(1):1-22.

3. Khan MI, Soofi SB, Ochiai RL, Khan MJ, Sahito SM, Habib MA, Puri MK, von Seidlein L, Park JK, You YA, Ali M, Nizami SQ, Acosta CJ, Sack RB, Clemens JD, Bhutta ZA (2012) Epidemiology, clinical presentation, and patterns of drug resistance of Salmonella Typhi in Karachi, Pakistan. J Infect Dev Ctries 6:704-714

4. Eberth CJ. Die Organismen in den Organen bei Typhus abdominalis. Archiv für pathologische Anatomie und Physiologie und für klinische Medicin. 1880 Jul 1;81(1):58-74. 
5. Gilman R, Terminel M, Levine M, Hernandez-Mendoza $P$, Hornick R. Relative efficacy of blood, urine, rectal swab, bone-marrow, and rose-spot cultures for recovery of Salmonella typhi in typhoid fever. The Lancet. 1975 May 31;305(7918):1211-3.

6. Afzal A, Sarwar Y, Ali A, Maqbool A, Salman M, Habeeb MA, Haque A. Molecular evaluation of drug resistance in clinical isolates of Salmonella enterica serovar Typhi from Pakistan. The Journal of Infection in Developing Countries. 2013 Dec 15;7(12):929-40.

7. Mirza SH, Beechmg NJ, Hart CA. Multi-drug resistant typhoid: a global problem. Journal of medical microbiology. 1996 May 1;44(5):317-9.

8. Qamar FN, Azmatullah A, Kazi AM, Khan E, Zaidi AK. A three-year review of antimicrobial resistance of Salmonella enterica serovars Typhi and Paratyphi A in Pakistan. The Journal of Infection in Developing Countries. 2014 Aug 13;8(08):981-6.

9. Mirza SH, Khan MA. Low-level quinolone-resistance in multi-drug resistant typhoid. J Coll Physicians Surg Pak. 2008 Jan 1;18(1):13-6.

10. Parry CM. The treatment of multidrug-resistant and nalidixic acid-resistant typhoid fever in Viet Nam. Transactions of the Royal Society of Tropical Medicine and Hygiene. 2004 Jul 1;98(7):413-22.

11. Hasan R, Cooke FJ, Nair S, Harish BN, Wain J. Typhoid and paratyphoid fever. The Lancet. 2005 Nov 5;366(9497):1603-4.

12. Klemm EJ, Shakoor S, Page AJ, Qamar FN, Judge K, Saeed DK, Wong VK, Dallman TJ, Nair S, Baker $S$, Shaheen G. Emergence of an extensively drugresistant Salmonella enterica serovar Typhi clone harboring a promiscuous plasmid encoding resistance to fluoroquinolones and third-generation cephalosporins. MBio. 2018 Mar 7;9(1):e00105-18.

13. Saha SK, Talukder SY, Islam M, Saha S. A highly ceftriaxone-resistant Salmonella typhi in Bangladesh. The Pediatric infectious disease journal. 1999 Apr 1;18(4):387.

14. Hasan R, Zafar A, Abbas Z, Mahraj V, Malik F, Zaidi A (2008) Antibiotic resistance among Salmonella enterica serovars Typhi and Paratyphi A in Pakistan (2001-2006). J Infect Dev Ctries 2:289-294.

15. Durr-e-Nayab, 2011. "Estimating the middle class in Pakistan," PIDE-Working Papers 2011:77, Pakistan Institute of Development Economics.

16. Capoor MR, Nair D. Quinolone and cephalosporin resistance in enteric fever. Journal of global infectious diseases. 2010 Sep;2(3):258.
17. Akhtar S, Sarker MR, Jabeen K, Sattar A, Qamar A, Fasih N. Antimicrobial resistance in Salmonella enterica serovar typhi and paratyphi in South Asiacurrent status, issues and prospects. Critical reviews in microbiology. 2015 Oct 2;41(4):536-45.

18. Qamar FN, Yousafzai MT, Khalid M, Kazi AM, Lohana H, Karim S, Khan A, Hotwani A, Qureshi S, Kabir F, Aziz F. Outbreak investigation of ceftriaxone-resistant Salmonella enterica serotype Typhi and its risk factors among the general population in Hyderabad, Pakistan: a matched case-control study. The Lancet Infectious Diseases. 2018 Dec 1;18(12):1368-76.

19. Aziz S, Malik L. Emergence of Multi-Resistant Enteric Infection In A Paediatric Unit Of Karachi, Pakistan. Age. 2018;5:2-84.

20. Naheed A, Ram PK, Brooks WA, Hossain MA, Parsons MB, Talukder KA, Mintz E, Luby S, Breiman RF. Burden of typhoid and paratyphoid fever in a densely populated urban community, Dhaka, Bangladesh. International Journal of Infectious Diseases. 2010 Sep 1;14:e93-9.

21. Williams PC, Isaacs D, Berkley JA. Antimicrobial resistance among children in sub-Saharan Africa. The Lancet Infectious Diseases. 2018 Feb 1;18(2):e3344.

22. Misra RN, Bawa KS, Magu SK, Bhandari S, Nagendra A, Menon PK. Outbreak of multi-drug resistant Salmonella Typhi enteric fever in Mumbai Garrison. Medical Journal Armed Forces India. 2005 Feb $1 ; 61(2): 148-50$.

23. Ram PK, Naheed A, Brooks WA, Hossain MA, Mintz ED, Breiman RF, Luby SP. Risk factors for typhoid fever in a slum in Dhaka, Bangladesh. Epidemiology \& Infection. 2007 Apr;135(3):458-65.

24. Yan M, Li X, Liao Q, Li F, Zhang J, Kan B. The emergence and outbreak of multidrug-resistant typhoid fever in China. Emerging microbes \& infections. 2016 Jan $1 ; 5(1): 1-6$.

25. Khan MI, Ochiai RL, Soofi SB, VON-SEIDLEIN L, Khan MJ, Sahito SM, Habib MA, Puri MK, Park JK, You YA, Ali M. Risk factors associated with typhoid fever in children aged 2-16 years in Karachi, Pakistan. Epidemiology \& Infection. 2012 Apr;140(4):665-72.

26. Sharma PK, Ramakrishnan R, Hutin Y, Manickam P, Gupte MD. Risk factors for typhoid in Darjeeling, West Bengal, India: evidence for practical action. Tropical Medicine \& International Health. 2009 Jun;14(6):696702. 
27. World Health Organization. Typhoid vaccines: WHO position paper, March 2018-Recommendations. Vaccine. 2019 Jan 7;37(2):214-6.

28. Britto CD, Wong VK, Dougan G, Pollard AJ. A systematic review of antimicrobial resistance in Salmonella enterica serovar Typhi, the etiological agent of typhoid. PLoS neglected tropical diseases. 2018 Oct 11;12(10):e0006779.
29. Antillón M, Bilcke J, Paltiel AD, Pitzer VE. Costeffectiveness analysis of typhoid conjugate vaccines in five endemic low-and middle-income settings. Vaccine. 2017 Jun 14;35(27):3506-14.

\section{AUTHORSHIP AND CONTRIBUTION DECLARATION}

\begin{tabular}{|c|c|c|c|}
\hline Sr. \# & Author(s) Full Name & Contribution to the paper & Author(s) Signature \\
\hline 1 & Tayyaba Anwar & $\begin{array}{l}\text { Involved in all steps of study } \\
\text { proposal writing to conclusion. }\end{array}$ & \\
\hline 2 & $\begin{array}{l}\text { Heena Rais } \\
\text { Madiha Fatima Jamil }\end{array}$ & $\begin{array}{l}\text { Involved in all steps of study, } \\
\text { Proposal writing to conclusion. } \\
\text { Data collection }\end{array}$ & \\
\hline 4 & Saba Safdar & Data analysis & Sa \\
\hline 5 & Muhammad Rafay Amir & Data collection & \\
\hline 6 & Ahmed Altaf & Data collection & \\
\hline 7 & Hira Khan & Data collection & Higa. \\
\hline
\end{tabular}

